\title{
LETRAMENTO MATEMÁTICO NOS ANOS INICIAIS DO ENSINO FUNDAMENTAL EM UMA PRÁTICA DOCENTE INSUBORDINADA CRIATIVAMENTE
}

\author{
MATHEMATICAL LETTERING IN THE INITIAL YEARS OF FUNDAMENTAL EDUCATION \\ IN A CREATIVELY INSUBORDINATED TEACHING PRACTICE
}

\author{
ADRIANO SANTOS DE MESQUITA ${ }^{1}$ \\ REGINA CÉLIA GRANDO²
}

\section{RESUMO}

Neste artigo, a partir de uma prática pedagógica insubordinada criativamente, analisamos as estratégias matemáticas adotadas por alunos de uma turma de $5^{\circ}$ ano do Ensino Fundamental de uma escola pública da rede estadual da cidade de Belém-PA relativas às tomadas de decisão importantes para o bem-estar coletivo. Nesse âmbito, nosso objetivo é identificar e compreender práticas de letramento matemático escolar assumidas por alunos dos anos iniciais em tomadas de decisões importantes frente a proposta insubordinada criativamente pelo professor pesquisador. Para a produção do material empírico utilizamos uma situação hipotética com o intuito de fomentar discussões pelos alunos; e nossos registros em áudio e em diário de campo acerca das reflexões dos estudantes, suscitadas pela situação hipotética. Constatamos que, quando diante de circunstâncias que demandam posicionamento, as crianças acessam o conhecimento matemático como estratégia para tomadas de decisão que impactam socialmente em suas vidas e de sua comunidade.

Palavras-chave: Letramento matemático. Tomada de decisão. Insubordinação criativa.

\section{ABSTRACT}

In this paper, from a creatively insubordinate pedagogical practice, we analyze the mathematical strategies adopted by students in a 5th grade class of a public elementary school in the state network of the city of Belém-PA regarding important decision-making for the good -being collective. In this context, our objective is to identify and understand school mathematical literacy practices assumed by students of the early years in making important decisions in view of the creatively insubordinate proposal by the researcher professor. For the production of empirical material we use a hypothetical situation in order to encourage discussions by students; and our audio and field diary records about students' reflections, raised by the hypothetical situation. We found that when faced with circumstances that demand positioning, children access mathematical knowledge as a strategy for decision making that has a social impact on their lives and their community.

Keywords: Mathematical literacy. Decision making. Creative insubordination.

\section{RESUMEN}

En este artículo, a partir de una práctica pedagógica creativamente insubordinada, analizamos las estrategias matemáticas adoptadas por los estudiantes en una clase de quinto grado de la escuela primaria en una escuela pública en la red estatal de la ciudad de Belém-PA con respecto a la toma de decisiones importantes para el bien -ser colectivo. En este contexto, nuestro objetivo es identificar y comprender las prácticas escolares de alfabetización matemática asumidas por los estudiantes de los primeros años al tomar decisiones importantes en vista de la propuesta creativamente insubordinada del profesor investigador. Para la producción de material empírico usamos una

1 Doutorando em Educação Científica e Tecnológica. Universidade Federal de Santa Catarina. E-mail: drykosantos@gmail.com. Orcid: https:// orcid.org/0000-0002-4322-4560.

2 Doutora em Educação. Universidade Federal de Santa Catarina. E-mail: regrando@yahoo.com.br. Orcid: https://orcid.org/0000-0002-2775-0819. 
situación hipotética para alentar las discusiones de los estudiantes; y nuestro diario de audio y de campo registra las reflexiones de los estudiantes, planteadas por la situación hipotética. Descubrimos que, cuando se enfrentan a circunstancias que exigen posicionamiento, Ios niños acceden al conocimiento matemático como una estrategia para la toma de decisiones que tiene un impacto social en sus vidas y en su comunidad.

Palabras-clave: Alfabetización matemática. Toma de decisiones. Insubordinación creativa.

\section{CONSIDERAÇÕES INICIAIS}

0 ensino de matemática nos anos iniciais do Ensino Fundamental lamentavelmente tem se caracterizado, em muitas instituições de ensino, como um instrumento voltado à manutenção da disciplina, da exclusão e, sobretudo, desvinculado da vida dos alunos. Acreditamos que, cursos que formam professores para atuarem nesse nível de ensino, especialmente os de pedagogia, necessitam reformular seus currículos no sentido de possibilitarem aos professores em formação inicial, competências e habilidades para a docência em matemática sustentadas nas práticas sociais com as quais os estudantes mantêm relação cotidiana.

Levando em consideração o conceito de insubordinação criativa como uma postura didático-pedagógica docente que rompe com o padrão com vistas à melhoria da qualidade da educação, neste trabalho analisamos as estratégias matemáticas adotadas por alunos de uma turma de $5^{0}$ ano do Ensino Fundamental de uma escola pública da rede estadual da cidade de Belém-PA relativas às tomadas de decisão importantes para o bem-estar coletivo. Nesse âmbito, nosso objetivo é identificar e compreender práticas de letramento matemático escolar assumidas por alunos dos anos iniciais em tomadas de decisões importantes frente a proposta insubordinada criativamente pelo professor pesquisador.

A questão de pesquisa se expressa nos seguintes termos: a partir de uma prática pedagógica insubordinada criativamente, que estratégias matemáticas, assumidas por alunos dos anos iniciais, contribuem para tomadas de decisão importantes e permitem supô-los matematicamente letrados?

Entendemos o letramento matemático na perspectiva dos usos sociais que, enquanto cidadãos, podemos fazer do conhecimento matemático em nossas relações diárias. Nos anos iniciais do Ensino Fundamental, desde que possibilitadas as condições, o conhecimento matemático tende a contribuir para que tomadas de decisão importantes sejam consideradas pelas crianças em situações reais de uso, a exemplo de saberem contar o tempo restante para o intervalo escolar ou para a saída.

De acordo com a Base Nacional Comum Curricular (BRASIL, 2016, p. 221) no Ensino Fundamental espera-se que os alunos "[...] desenvolvam a capacidade de identificar oportunidades de utilização da matemática para resolver problemas, aplicando conceitos, procedimentos e resultados para obter soluções e interpretá-las segundo os contextos das situações". Assim, rompe-se com a ideia inicial de que o ensino de matemática seja assumido para manter a disciplina escolar, a exclusão e não tenha relação com a vida prática dos estudantes.

Além dessa seção introdutória, desenvolvemos esse artigo em mais três seções: na próxima apresentamos os referenciais teóricos que assumimos para tratar do letramento matemático em práticas sociais em que o conhecimento matemático se faz necessário, e da insubordinação criativa como postura didático-pedagógica presente em atitudes docentes; em seguida, destacamos os caminhos metodológicos que nos permitiram a elaboração do presente estudo; e, na terceira seção, analisamos as tomadas de decisão de alunos de uma turma de $5^{0}$ ano do Ensino Fundamental na perspectiva do letramento matemático. 


\section{LETRAMENTO MATEMÁTICO E INSUBORDINAÇÃO CRIATIVA}

Nessa seção nosso objetivo é apresentar uma breve revisão da literatura sobre o que alguns autores entendem em relação ao letramento matemático como prática social que possibilita tomadas de decisão importantes, e sobre a insubordinação criativa enquanto postura didático-pedagógica docente que contribui para que as tomadas de decisão possam ocorrer de maneira responsável garantindo melhoria da qualidade da educação.

0 termo "Letramento" surgiu no discurso de especialistas da área das Ciências Linguísticas, na segunda metade dos anos 1980. Um dos primeiros registros do termo pode ser verificado no livro "No mundo da escrita: uma perspectiva psicolinguística" de autoria de Mary Kato em 1986. Já em 1988, Leda Verdiani Tfouni, no livro "Adultos não alfabetizados: 0 avesso do avesso", faz a distinção entre alfabetização e letramento. A partir de então, o vocábulo ganha espaço no discurso de especialistas (SOARES, 2004).

Soares (2004) esclarece que a palavra "letramento" não é registrada por haver sido introduzida recentemente na língua portuguesa, mas que apareceu no Dicionário Contemporâneo da Língua Portuguesa, de Caldas Aulete, publicado há mais de cem anos com o significado de "escrita". Porém, apesar da aparição no dicionário, a autora explica que o sentido atual atribuído ao termo vem da tradução da palavra inglesa literacy, à qual é conferido o estado ou a condição assumido por quem aprende a ler e escrever. Soares (2004, p. 18) ainda explica que, em língua portuguesa, a palavra literacy passou a ser traduzida literalmente por "letramento" denotando "[...] o resultado da ação de aprender a ler e escrever: o estado ou a condição de um grupo social ou um indivíduo como consequência de ter-se apropriado da escrita".

Em educação matemática, o letramento também tem sido investigado todas as vezes que usamos o conhecimento matemático nas relações sociais que estabelecemos em nosso cotidiano. Nesse sentido, no Brasil, muitos pesquisadores (GALVÃO; NACARATO, 2013; GRANDO; NACARATO; LOPES, 2014; GRANDO, 2016; MESQUITA, 2019) têm se dedicado ao estudo do letramento matemático como estratégia para melhorar o desempenho dos alunos e suas habilidades em saber relacionar 0 conhecimento à realidade vivida.

Acreditamos, veementemente, que, nos anos iniciais do Ensino Fundamental, práticas pedagógicas envolvendo o conhecimento matemático para a resolução de problemas do dia a dia se constituem em aprendizagem significativa para as crianças, pois, além dos conteúdos matemáticos envolvidos, os alunos têm a possibilidade de experimentar tomadas de decisão importantes para 0 bem individual e coletivo.

Considerando que "a matemática é uma das formas que nós, seres humanos, usamos para interpretar, explicar e compreender o mundo [...]" (RIBEIR0, 2018, p. 35), nossa intenção é afirmar a necessidade de desenvolvimento de uma matemática escolar contextualizada à vida prática dos estudantes por meio de atividades pedagógicas que motivem a curiosidade das crianças e as façam perceber a presença dessa disciplina em tarefas rotineiras com as quais mantêm contato em suas relações diárias, a exemplo da leitura que se pode fazer das faturas de energia ou de água enquanto serviços que usualmente são utilizados.

A esse respeito, Mesquita (2019, p. 315) afirma:

Fazer uso da Matemática com responsabilidade social permite aos alunos e aos seres humanos, de forma geral, que detenham diversas habilidades, dentre elas: a de saber ler e interpretar gráficos e tabelas, instrumentos esses muito difundidos 
atualmente, sobretudo por pesquisas de opinião realizadas por órgãos competentes; interpretar contas de luz, água, telefone, que são servições presentes na vida do cidadão e sobre os quais incidem impostos; saber organizar a economia pessoal; compreender dados sobre peso, altura, medidas e suas implicações para a saúde.

0 uso do conhecimento matemático com responsabilidade social, conforme defendido pelo autor, permite aos estudantes de anos iniciais aproximação com o vivido, o experienciado. Serviços de água, luz e telefonia, por exemplo, constituem-se em obrigações sociais com as quais, ainda que de forma indireta, as crianças mantêm relação de proximidade. Para ler e compreender esses documentos noções mínimas de matemática são indispensáveis e, por esse motivo, desenvolver atividades que envolvam o letramento matemático torna-se imprescindível na realização da atividade pedagógica.

Nesse âmbito, o letramento matemático é definido na relação que se estabelece entre práticas sociais e a matemática, sendo entendido como a:

[...] capacidade do sujeito de colocar e resolver problemas matemáticos em situações diversas, quando passa a exercer uma relação direta entre práticas sociais e a matemática, de modo que o conhecimento matemático não esteja apenas ligado ao contexto escolar, mas antes relacionado aos usos específicos de um determinado grupo social (CIRÍACO; SOUZA, 2011, p. 45)

Consideradas em contexto, práticas sociais e matemática, segundo Ciríaco e Souza (2011), fundamentam as bases do letramento matemático que, ao contribuir para a construção de conhecimentos específicos em situações reais de uso, extrapola 0 ambiente escolar e, portanto, não se limita a este. É comum, no dia a dia, crianças se encontrarem diante de circunstâncias em que 0 conhecimento matemático se impõe como necessário para a resolução de problemas corriqueiros, a exemplo da contagem dos dias para seu aniversário, da divisão justa dos doces que ganharam, ou do entendimento do valor de um produto.

Os autores também consideram letramento matemático as práticas rotineiras, como as já citadas, nas quais indivíduos utilizam conhecimentos matemáticos diante de demandas sociais. Ou ainda, podemos dizer que o letramento matemático, em sua concepção, refere-se a "[...] evento ou prática em que 0 uso específico de conhecimentos matemáticos se associa em determinadas situações da vida cotidiana do indivíduo, que passa a produzir saberes matemáticos nas ações diárias" (CIRÍACO; SOUZA, 2011, p. 43).

Com perspectiva de pensamento semelhante, Grando (2016, p. 03) ensina que um cidadão letrado matematicamente é:

[...] capaz de analisar situações, compreender dados e informações, levantar hipóteses, resolver problemas, sistematizar e comunicar ideias. As práticas de letramento matemático escolar são entendias como atividades desenvolvidas com alunos na perspectiva da formação de um cidadão letrado matematicamente.

Ou seja, o cidadão matematicamente letrado é um indivíduo ativo e envolvido em práticas sociais de uso do conhecimento matemático. De acordo com a autora, esse indivíduo analisa situações, interpreta dados e informações, elabora hipóteses, resolve problemas, além de sistematizar ideias, ações importantes no contexto da matemática associada a práticas sociais. 
Embora ativo no processo de construção do conhecimento matemático, o cidadão considerado letrado matematicamente não é solitário em suas ações. Por isso acreditamos no letramento matemático como um processo de produção colaborativa que implica em transformações no cotidiano escolar (GRANDO; NACARATO; LOPES, 2014). Entendemos que tais transformações devem ocorrer a partir de eventos da realidade social em que os estudantes se encontram inseridos e sobre a qual produzem sua existência.

Ainda nesse contexto, corroborando as percepções anteriormente apresentadas por Mesquita (2019), podemos dizer que o letramento matemático contribui para que os estudantes dos anos iniciais saibam:

[...] aplicar as práticas de leitura, escrita matemática e habilidades matemáticas para resolver problemas não somente escolares, mas de práticas sociais como: saber ler e interpretar gráficos e tabelas, fazer estimativas, interpretar contas de luz, telefone, água e demais ações relacionadas aos diferentes usos sociais (GALVÃO; NACARATO, 2013, p. 84).

As ações acima elencadas permitem que, não apenas estudantes, mas os indivíduos em geral, possam agir criticamente na sociedade sabendo tomar decisões responsáveis quando estas se fazem necessárias. Destacamos que as práticas de leitura e escrita matemática referidas por Galvão e Nacarato (2013) são igualmente importantes no processo de letramento matemático na perspectiva da tomada de decisão, pois contribuem para a formação de indivíduos matematicamente letrados.

A Base Nacional Comum Curricular, enquanto documento normativo e de referência para a elaboração de currículos escolares e propostas pedagógicas, estabelece que 0 ensino fundamental deve ter compromisso com o desenvolvimento do letramento matemático, sendo este definido como:

[...] as competências e habilidades de raciocinar, representar, comunicar e argumentar matematicamente, de modo a favorecer 0 estabelecimento de conjecturas, a formulação e a resolução de problemas em uma variedade de contextos, utilizando conceitos, procedimentos, fatos e ferramentas matemáticas. É também o letramento matemático que assegura aos alunos reconhecer que os conhecimentos matemáticos são fundamentais para a compreensão e a atuação no mundo e percebe 0 caráter de jogo intelectual da matemática, como aspecto que favorece o desenvolvimento do raciocínio lógico e crítico, estimula a investigação e pode ser prazeroso (fruição) - (BRASIL, 2016, p. 222).

Ainda segundo o documento, embora, por excelência, a matemática seja uma ciência hipotético-dedutiva, é imprescindível considerar seu papel heurístico nas experimentações de aprendizagens que promove (BRASIL, 2016). Sendo assim, o letramento matemático garante aos estudantes que relacionem observações empíricas - como as citadas por Mesquita (2019) e por Galvão e Nacarato (2013) - a representações na forma de tabelas, gráficos, estimativas, também já referenciadas pelos autores.

Ainda no contexto de tomadas de decisão, outro conceito importante para o presente estudo é 0 da insubordinação criativa (IC) que, em nosso país, tem sido frequente em trabalhos como 0 nosso, que tratam da educação matemática. É recorrente, nessa área do conhecimento, contato com estudos na perspectiva do trabalho desenvolvido por professores que se utilizam de práticas insubordinadas criativamente com o intuito de contribuir para a formação de estudantes reflexivos e 
críticos. Nas próximas linhas apontamos caminhos para 0 desenvolvimento da insubordinação criativa especialmente no âmbito dos anos iniciais.

A expressão Insubordinação Criativa surge em 1981 em um relatório publicado por Morris et al. (1981) relativo a um estudo etnográfico desenvolvido com dezesseis diretores de escolas de Chicago em que se apresentavam discussões a respeito da IC como recurso diante da burocracia educacional; assim, os gestores sentiam a necessidade de desobedecer ordens de diretrizes superiores, tomando decisões responsáveis, em prol do bem-estar da comunidade educativa de modo a resguardar princípios éticos, morais e de justiça social. Ao final da década de 1980 a Enfermagem se apropria de tais ideias e passa a usar o termo "subversão responsável" para se referir às quebras de protocolo por seus profissionais na tentativa de garantir proteção e melhores condições aos pacientes (D'AMBROSIO; LOPES, 2015).

No Brasil, D’Ambrosio e Lopes (2014; 2015, contracapa), educadoras matemáticas, constituem-se em alguns dos nomes ligados à difusão da insubordinação criativa em práticas pedagógicas de profissionais da educação. Para estas autoras:

0 conceito de insubordinação criativa se refere às ações de rupturas assumidas diante às normas ou regras institucionais visando um melhor atendimento às necessidades das pessoas às quais se prestam serviço. No caso da educação são considerados subversivamente responsáveis os gestores e professores que criam alternativas criativas para obterem melhores resultados para 0 bem comum da comunidade escolar constituída por seus colegas, alunos e pais como uma ação de oposição e, geralmente, de desafio à autoridade estabelecida quando esta se contrapõe ao bem do outro, mesmo que não intencional, por meio de determinações incoerentes, excludentes e/ou discriminatórias.

Destacamos que, romper com normas ou regras institucionais não significa, portanto, deixar de realizar qualquer que seja a atividade designada, mas desenvolvê-la na perspectiva de melhor atendimento do serviço que se presta. Relativo à educação, ser insubordinado criativamente requer, assim, estabelecer alternativas que visem o bem da comunidade. Dessa forma, ocorre uma ação de oposição à autoridade estabelecida, mas levando em consideração decisões responsáveis (D’AMBROSIO; LOPES, 2014)

No espaço da escola, os professores normalmente são os mais insubordinados criativamente diante de situações que se impõem. Segundo D’Ambrosio e Lopes (2014, p. 29), para que professores tenham atitudes de insubordinação criativa, deverão "[...] ter clareza sobre o contexto social, político e cultural que historicamente influencia os processos de produção do conhecimento humano [...]". 0 referido contexto, por vezes, "[...] promove 0 individualismo ao invés da interação, a reprodução de saberes ao invés da criação, o ocultamento ao invés da socialização de ideias, a competição ao invés da colaboração" (D’AMBROSIO; LOPES, 2014, p. 29). É exatamente contra tudo isso que práticas de IC se insurgem.

Nessa linha de pensamento percebemos que os professores - e aqui chamamos a atenção particularmente àqueles que ensinam matemática e as disciplinas de educação geral nos primeiros anos de escolarização - são preparados, em cursos de formação docente, para cumprir e obedecer ordens, sejam estas das secretarias de educação, da direção da escola ou de coordenadores pedagógicos. Com frequência precisam ensinar conteúdos predeterminados com o único objetivo de submeterem os alunos a testes padronizados elaborados por municípios, estados e pelo Ministério da Educação. 
Ser criativo e se insubordinarem no sentido de não seguir rigorosamente as orientações propostas pelas autoridades educacionais estabelecidas é um ato de IC, a qual também pode ser definida como segue:

Insubordinação criativa é ter consciência sobre quando, como e por que agir contra procedimentos ou diretrizes estabelecidas. Ser subversivamente responsável requer assumir-se como ser inconcluso, que toma a curiosidade como alicerce da produção de conhecimento e faz de seu inacabamento um permanente movimento de busca (D'AMBROSIO; LOPES, 2015, p. 29).

Inspiradas por Freire (1996), as autoras chamam a atenção dos professores para a necessidade de discernirem em quais momentos da atividade docente podem e devem ser insubordinados criativamente. Para isso, é pertinente se assumirem inconclusos, ou seja, tenham consciência de que não sabem tudo e que o exercício da profissão é permeado de uma constante busca em saber um pouco mais. Sob essa ótica, não seguir conteúdos previamente deliberados e para fins avaliativos, como mencionamos acima, também é uma atitude insubordinada criativamente.

Concordamos com Longo (2015, p. 104) que, ao escrever sobre como os professores se constituem naturalmente insubordinados, afirma: "[...] para se constituir naturalmente insubordinada, é preciso ter criatividade, é preciso ter coragem, é preciso desviar das pedras, desviar das enxurradas, desviar dos empurrões, em prol de um objetivo [...]". A autora faz referência ao próprio trabalho enquanto professora ao mesmo tempo em que generaliza afirmando que, inclusive, o trabalho pedagógico desenvolvido por professores é considerado naturalmente insubordinado. 0 objetivo a que ela se refere está ligado diretamente à aprendizagem do aluno que, em nosso caso, é relativo ao ensino de matemática nos anos iniciais.

Com postura semelhante, encontramos em D'Ambrosio e Lopes (2015) considerações a respeito da autonomia docente como elemento fundamental para atitudes de IC. As pesquisadoras indicam que a autonomia, na prática pedagógica, entendida como o processo de ensino e de aprendizagem que ocorre no espaço da sala de aula, deve ser exercida com compromisso político e com ética, 0 que leva a uma construção reflexiva sobre o processo de ensino e de aprendizagem. Argumentam, ainda, que, para a formação de estudantes criativos, os professores também devem ter o mesmo adjetivo. Concluem com o seguinte pensamento: "A criatividade humana precisa ser direcionada para ações positivas e em prol do bem-estar humano, com cuidado, para não comprometer a ética e 0 respeito ao outro" (D'AMBROSIO; LOPES, 2015, p. 10).

Encontramos em Garnica (2014, p. 18-19) o seguinte posicionamento sobre o que considera insubordinação criativa. É possível observar o destaque dado pelo autor para as posturas de alerta que 0 insubordinado criativo deve ter:

Insubordinação implica subversão, implica uma aposta no novo, no diferente e na insatisfação com relação tanto ao que é quanto ao que pode ser, aquilo que, tendo sido criado por ações insubordinadas, não pode ser aceito como natural e permanente. Uma insubordinação criativa, portanto, exige uma postura alerta, pois tudo que se faz novo pode - ou deve - se desfazer nesse nosso mundo de constantes mudanças. Talvez um insubordinado criativo nunca seja, em definitivo, insubordinado criativo: num perigoso gerúndio, ele sempre está sendo. Num mundo em que tudo tende a se tornar opaco e contaminado pelas restrições - normas, exigências, legislações, 
poderes e instituições - que controlam o dia a dia, o insubordinado criativo deve sempre estar em alerta, colocando em suspeição até mesmo o caráter subversivo de suas insubordinações.

Insubordinar-se, portanto, significa se subverter, mas uma subversão com aposta no diferente e na insatisfação ao que está posto, determinado. A IC, na visão de Garnica (2014) requer postura alerta para mudanças que devem surgir, requer ousadia pedagógica na esperança de melhores resultados. Concebemos o direito à liberdade de pensar - a autonomia - e 0 direito de questionar como posturas que tendem a colocar o indivíduo em alerta, ao mesmo tempo possibilitam ruptura com normas ou exigências que não dão espaço à criatividade. No ensino de matemática nos primeiros anos de escolarização, a criatividade é fator que merece destaque, especialmente pelo conjunto de atividades disponíveis que aguçam a imaginação e a curiosidade das crianças.

Dessa forma, D'Ambrosio e Lopes (2015) ensinam que os professores, ao se depararem com a complexidade da sala de aula, devem encarar diversos dilemas e conflitos, diante dos quais precisam desenvolver estratégias e tomar decisões criativas. Essa ação é entendida como insubordinação criativa já que os educadores assumem, por meio de seu fazer pedagógico, imprevisibilidades que se materializam no processo de construção do conhecimento; assim, os alunos, passam a ter suas necessidades atendidas pelos professores que, em vez de seguirem diretrizes preestabelecidas pelas instituições, dedicam-se ao que emerge da própria prática de sala de aula ou da realidade experienciada pelas crianças.

Nesse sentido, concebemos a insubordinação criativa - uma ação contra um poder que subordina - como conceito importante que, semelhante ao letramento matemático, favorece a resolução de problemas do cotidiano educativo por meio do desenvolvimento da capacidade de atuação no e sobre o mundo, o que se torna imprescindível ao exercício da cidadania. No que diz respeito ao ensino de matemática nos anos iniciais do Ensino Básico, a insubordinação criativa permite que tomadas de decisão pertinentes sejam assumidas almejando sempre um bem coletivo. Ser insubordinado criativamente, nesse sentido, não significa simplesmente deixar de aceitar regras, normas ou preceitos, mas ter atitudes de ousadia pedagógica que garantam resultados de aprendizagem com qualidade elevada e para o bem comum.

\section{CAMINHOS METODOLÓGICOS}

Esta pesquisa assume caráter qualitativo na perspectiva de posturas insubordinadas criativamente no âmbito do letramento matemático como potencializador para tomadas de decisão. A pesquisa qualitativa, de acordo com Silva e Trintin (2017) preocupa-se em interpretar fenômenos não quantificáveis, além de permitir a atribuição de significados sobre as ações dos sujeitos.

A pesquisa está estruturada em três momentos associados entre si: no primeiro, apresentamos aos alunos uma situação hipotética, elaborada por nós mesmos, cujo objetivo foi o de possibilitar-lhes possíveis posicionamentos, necessariamente adotados, para tomadas de decisão. Para isso, além de divididos em grupos de quatro alunos, três questões foram sugeridas e sobre as quais os estudantes tiveram um tempo para conversar. No quadro 1 reproduzimos a situação e as questões. 
Quadro 1 - Situação hipotética e questões para reflexão.

\begin{tabular}{|l|}
\hline \multicolumn{1}{|c|}{ Considere a seguinte situação: } \\
\hline Após uma enchente, sua família - neste momento representada por você e por seus colegas de grupo - acabou perdendo \\
tudo, menos suas vidas e a casa onde moram. Para ajudá-los a enfrentar esse momento ruim, a comunidade da qual \\
vocês fazem parte, atingida em uma proporção menor, se organizou e, por meio de contribuições voluntárias, além de \\
alguns poucos utensílios de cama, mesa e banho, arrecadou a quantia de R\$ 5.000,00. Imaginem que uma loja colocou \\
à disposição de vocês alguns produtos (expostos nas paredes da sala de aula), além de gêneros alimentícios, e discu- \\
tam, em família, como vocês farão para usar esse valor levando em consideração seus conhecimentos em matemática \\
aprendidos na escola ou fora dela também. Observação: a mesma loja também encaminhou um vendedor (representado \\
por alunos que se revezavam na função) para auxiliá-los na compra dos produtos. \\
Questões para pensar: \\
1. O que é possível comprar com a quantia que temos? \\
2. É possível organizar os gastos? Como? \\
3. O conhecimento em matemática ajuda a saber usar o dinheiro? Como?
\end{tabular}

Fonte: Construção dos autores.

No segundo momento, por meio da dinâmica de compra e venda, os alunos puderam exercitar o poder de decisão mediante às escolhas que deveriam fazer para, então, comprar algo. Colocamos à disposição das crianças cédulas de real sem valor oficial para simular a circulação do dinheiro e para que elas manipulassem à vontade no sentido de perceberem as trocas que poderiam realizar. Registramos todo esse movimento por meio de vídeos e imagens que, quando necessários, usaremos tomando os devidos cuidados, relativos à ética, para não identificar os estudantes ou a instituição onde a pesquisa ocorreu.

0 terceiro momento foi subdividido em dois: i) socialização nos grupos anteriormente formados para sabermos que estratégias foram utilizadas pelos alunos para a compra dos produtos; ii) socialização, em roda de conversa, das impressões dos estudantes sobre a atividade realizada. Apresentamos os dois momentos sob a forma de diálogos dos pesquisadores com os alunos.

Para analisar o material empírico produzido lançamos mão de nossa análise interpretativa por contraste entre semelhanças e diferenças. Nos diálogos estabelecidos com os alunos, nós nos identificamos pela letra maiúscula P (pesquisadores) e aos estudantes usando a letra "E" (estudante) seguida de um algarismo para, como já mencionado, preservar a ética. Esses diálogos foram registrados em nosso diário de campo e constituem parte do corpus analisado. As etapas aqui descritas tiveram por objetivo contribuir para possíveis respostas à questão de pesquisa mencionada na seção anterior desse estudo.

\section{TOMADAS DE DECISÃO DE ALUNOS DOS ANOS INICIAIS NA PERSPECTIVA DO LETRAMENTO MATEMÁTICO}

Nesta seção analisamos as tomadas de decisão dos alunos, na perspectiva do letramento matemático, assumidas a partir da prática pedagógica da qual participaram. Por meio dos diálogos desenvolvidos com os estudantes, apresentamos trechos nos quais ficam evidentes aspectos em que posicionamentos responsáveis são adotados considerando o conhecimento matemático como importante recurso que contribui para processos de ensino e de aprendizagem. A insubordinação criativa é constatada por intermédio de nossa postura didático-pedagógica que visa estimular os estudantes 
às tomadas de decisão quando confrontados com uma situação diante da qual são instigados a manifestar atitudes seguras, as quais também podem ser consideradas insubordinadas criativamente.

Para ressaltar a importância da instituição escolar, enquanto instituição social, na promoção de situações que contribuam para a compreensão do cotidiano das crianças por meio do conhecimento matemático, assumimos que:

[...] a escola tem um papel importante na sistematização dos conhecimentos que as crianças, conhecedoras nativas da matemática de uso cotidiano, trazem para a escola e ainda o de ampliar seu repertório instrumental para ajudá-las a resolver as situações cotidianas e escolares cada vez com mais autonomia. 0 trabalho consiste em criar situações lúdicas e interessantes para as crianças que Ihes possibilitem estabelecer relações entre as noções matemáticas do uso cotidiano e as noções matemáticas escolares (RIBEIR0, 2018, p. 35-36).

Nutridos pela perspectiva de Ribeiro (2018), acreditamos e defendemos que a escola é esse espaço importante para o desenvolvimento de indivíduos autônomos, com capacidade de reflexão e preparados para estabelecer relações entre a matemática que naturalmente ocorre no cotidiano e os conhecimentos matemáticos ensinados nas instituições de ensino. Assim, enquanto pesquisadores, mas também na condição de docentes, concebemos as narrativas dos estudantes como indicativos de elementos que nos permitem apontar aspectos de quem pode ser considerado matematicamente letrado.

As figuras 1 e 2 mostram o processo inicial de reflexão feito pelos alunos. Nelas, as crianças observam, com atenção, os "produtos" expostos nas paredes da sala de aula e já iniciam suas análises a respeito das decisões a serem tomadas.

Figura 1 - Alunos observando os "produtos" expostos.

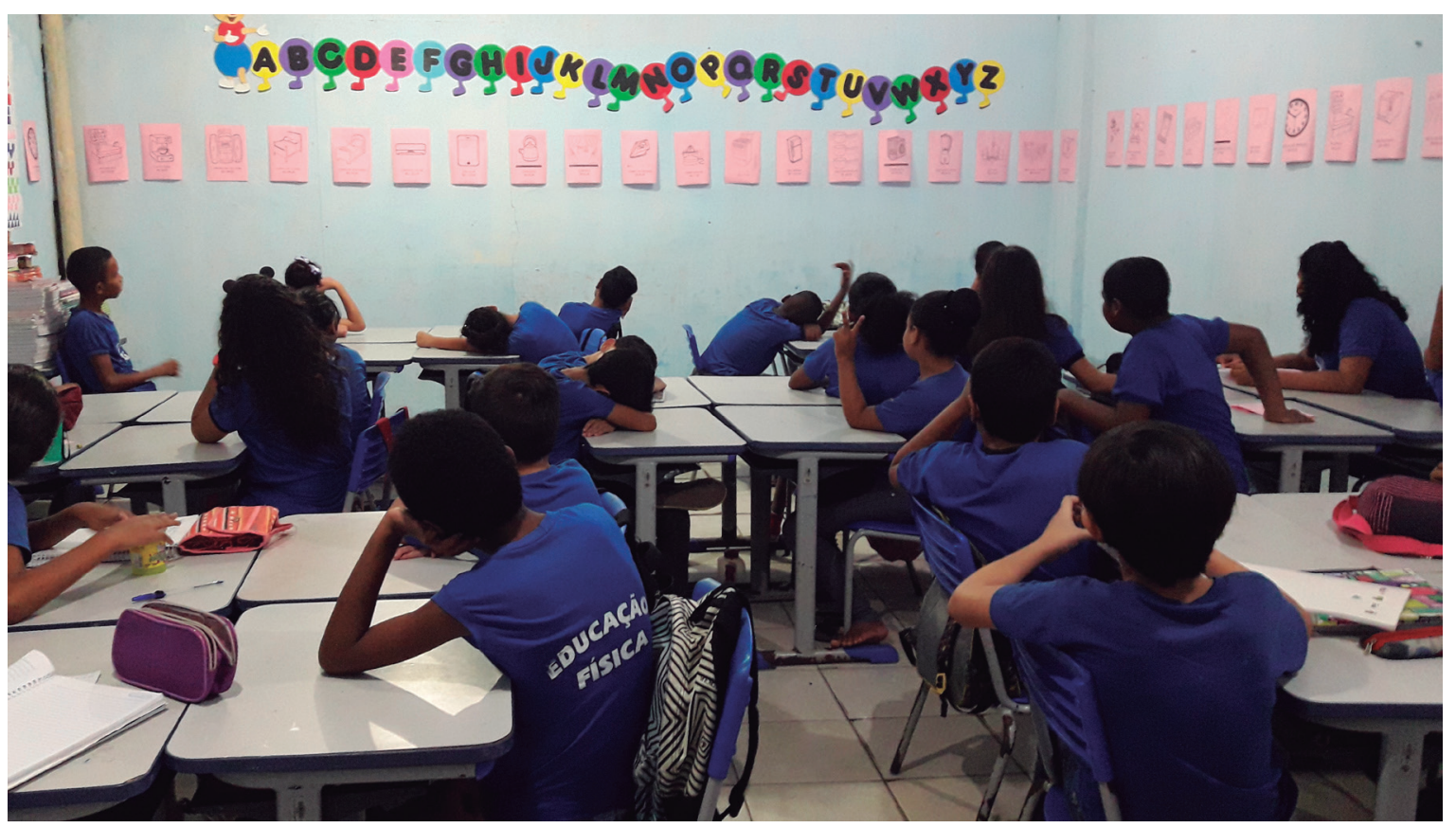

Fonte: Arquivo dos autores. 
Figura 2 - Análise das decisões a serem tomadas

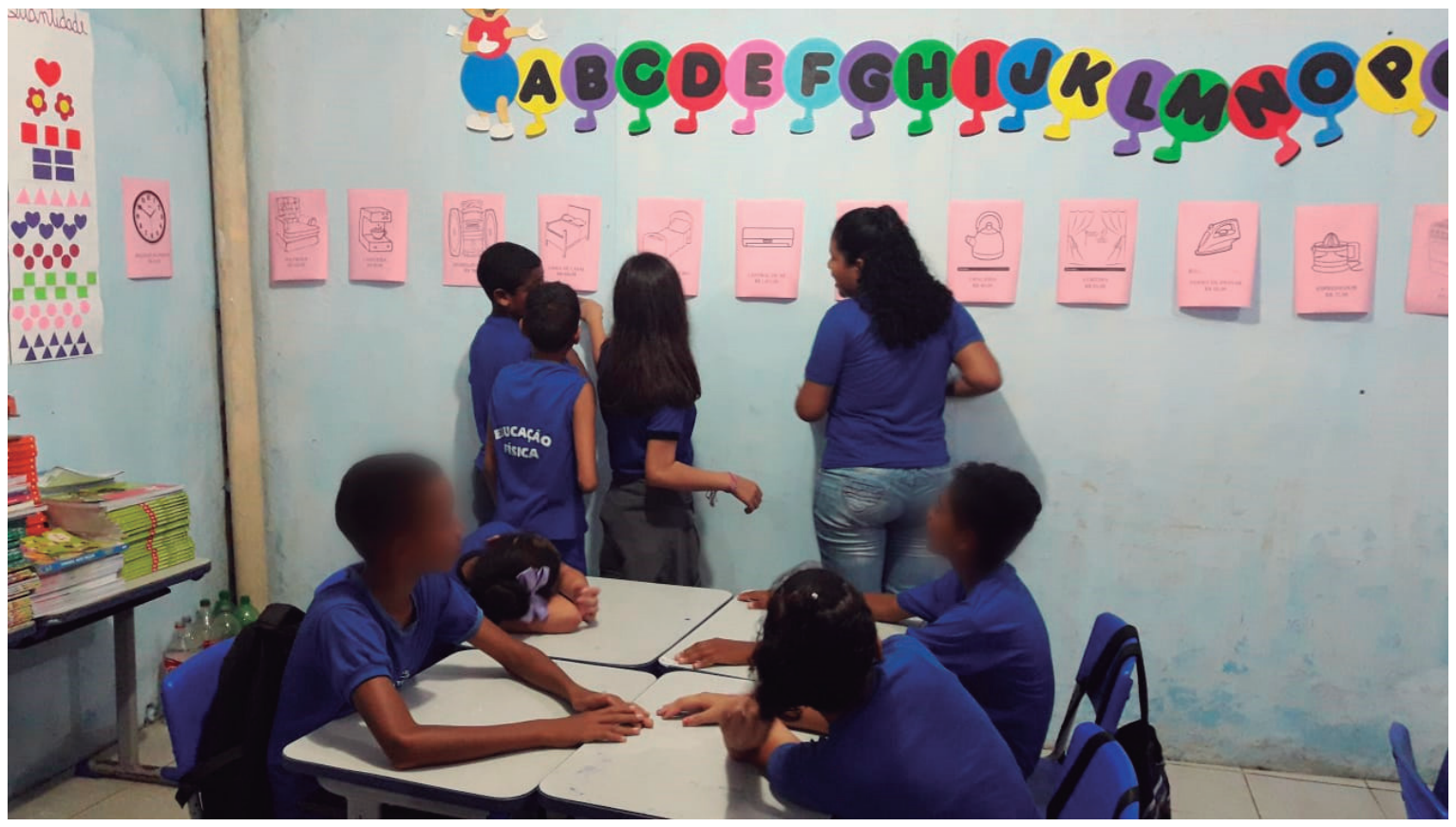

Fonte: Arquivo dos autores.

No trecho abaixo, após as análises feitas, fica evidente o posicionamento dos alunos quanto a tomadas de decisão responsáveis.

P: Vocês acham que compraram tudo o que era preciso?

E2: Eu acho que sim.

$\mathrm{P}:$ E por que não compraram o celular?

E1: Porque nesse momento não era importante e o dinheiro não ia dá.

$\mathrm{P:} 0$ que é mais importante?

E1: A comida, claro!

P: Mas por que a comida e não o celular?

E1: Porque o celular a gente usa pra jogar, mas a comida ajuda a gente a viver e é mais barata.

P: Mas a comida acaba e o celular dura mais. Vocês já pensaram nisso?

E4: É, mas como a gente não comprou o celular sobrou mais dinheiro e a gente pode comprar mais de novo. É só a gente saber gastar direito.

De acordo com os estudantes, além do momento vivenciado por eles - a situação hipotética da enchente que atingira sua família - optar pela aquisição de um aparelho celular não era adequado porque 0 montante disponível não permitia. 0 estudante 1 ao afirmar que "o dinheiro não ia dá", espontaneamente desenvolve um processo que envolve cálculo mental por estimativa para chegar a essa conclusão. A nosso ver o estudante estabelece uma relação clara de reflexão na ação, ou seja, 
caso adquirisse o celular, faltaria dinheiro para a compra de produtos mais urgentes. De forma semelhante, mas levando em consideração a noção de custo-benefício, o mesmo estudante, reage ao questionamento dirigido ao grupo afirmando que a comida, além de contribuir para a sobrevivência do ser humano, "é mais barata". A relação custo-benefício é claramente satisfeita quando se pensa que alimentos, nesse caso específico, além de apresentarem um custo mais baixo, também contribuem para a manutenção da vida.

Por sua vez, a estudante 4 revela compreensão implícita da noção de divisão em matemática, pois, ao afirmar que o grupo não comprou o celular e, por esse motivo, "sobrou mais dinheiro", a relação mental estabelecida envolve elementos característicos da operação de divisão realizada para que pudesse chegar à conclusão de que algo sobrou. Além disso, quando declara que é preciso "saber gastar direito", a estudante revela entendimento de economia sob a ótica da tomada de decisão para o bem coletivo.

A partir da atividade proposta, reafirmamos a importância de professores, particularmente os que desenvolvem a docência nos primeiros anos do Ensino Fundamental, manifestarem posturas insubordinadas criativamente expressando clareza quanto ao contexto sócio-político-cultural e sobre como este influencia na construção do conhecimento (D’AMBROSIO; LOPES, 2014). Tozetto (2010, p. 61), citando Carraher, Carraher, Schliemann (2006), afirma que, em contextos semeIhantes ao que propomos nesse estudo, "o papel do professor é integrar a matemática organizada cientificamente com a matemática da atividade humana, ou seja, a matemática da escola com a matemática da vida cotidiana".

Na perspectiva de integrar a matemática do dia a dia aos conhecimentos matemáticos escolares, segue o seguinte diálogo:

\section{P: Como vocês fizeram para organizar os gastos?}

E9: Eu pensei que a gente tinha pouco dinheiro e que, se a gente gastasse menos, ai sobraria mais pra depois.

$\mathrm{P}$ : E como você faria isso?

E9: Economizando.

$\mathrm{P}$ : De que forma?

E9: Eu precisava saber quanto custavam as coisas pra pedir abatimento.

"Pedir abatimento", como relatado pela estudante, é algo habitual na matemática das relações sociais que envolve compra e venda, sendo utilizado com frequência por muitas pessoas. Solicitar desconto é, portanto, a estratégia matemática encontrada pela estudante para conseguir economizar o dinheiro disponibilizado e, assim, "sobraria mais pra depois". Essa forma de gerenciar o dinheiro caracteriza um indivíduo com capacidade de raciocinar e argumentar matematicamente (BRASIL, 2016) com vistas a lograr êxito ao convencer o vendedor a reduzir o preço do produto desejado.

Na figura 3 pode-se perceber o grupo realizando um possível planejamento orçamentário para saber como economizar o dinheiro. 
Figura 3 - Planejamento orçamentário

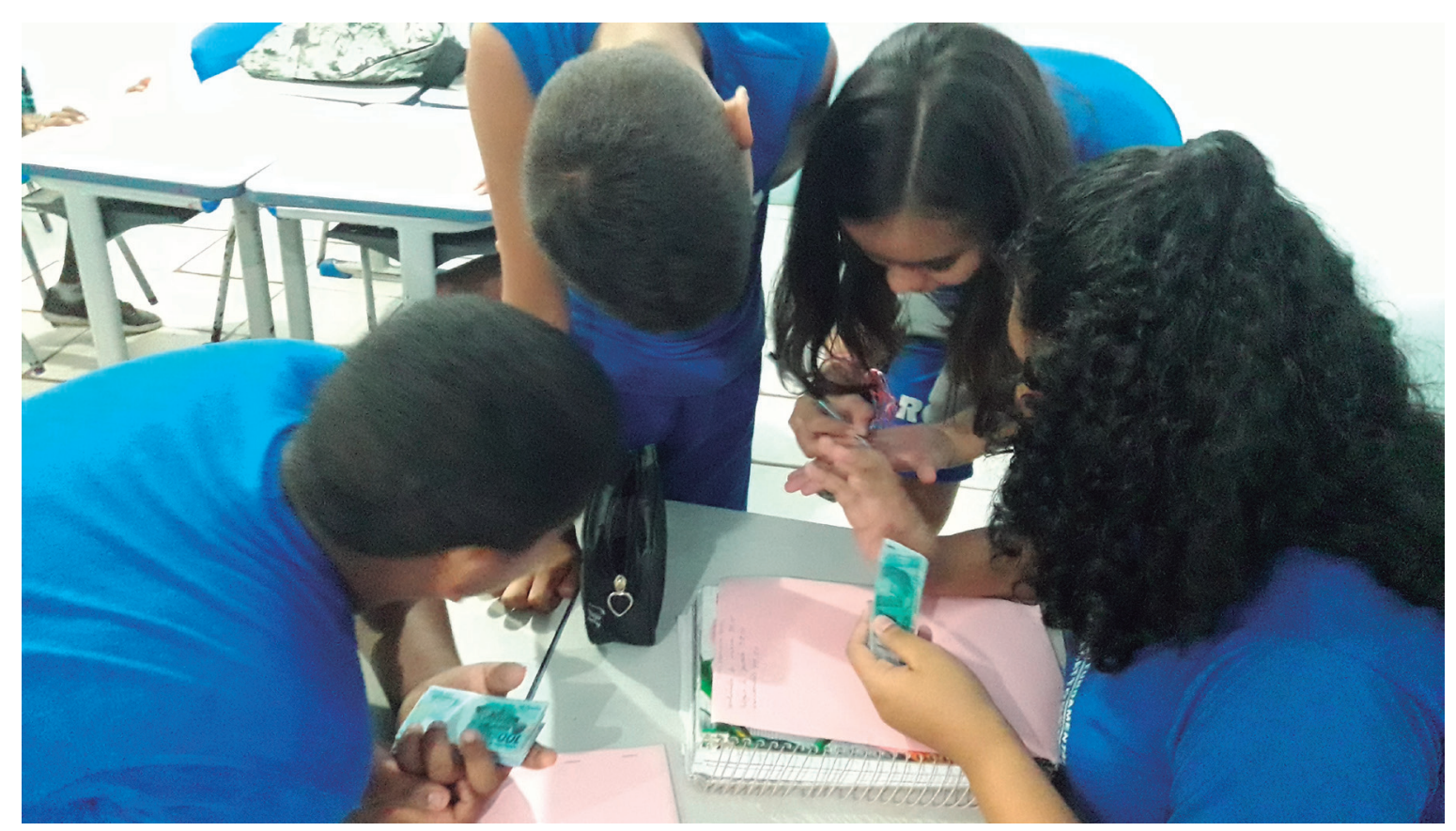

Fonte: Arquivo dos autores.

Ao colocar, a outro grupo, o mesmo questionamento sobre a forma de organização dos gastos, obtivemos respostas semelhantes ao do grupo anterior, contudo um dos alunos exemplifica com a própria vivência.

\section{P: Como vocês fizeram para organizar os gastos?} dinheiro.

E21: A gente achou melhor fazer um planejamento pra saber como a gente podia gastar 0

P: Como vocês fizeram esse planejamento?

E22: Eu achei que a gente precisava comprar primeiro o que era mais importante.

P: Por exemplo?

E22: A cama pra gente não dormir no chão, e comida pra não morrer de fome.

E23: A minha mãe sempre diz que a gente tem que pesquisar os preços pra depois comprar onde é mais barato e sobrar mais dinheiro.

$\mathrm{P}:$ E como vocês fizeram isso?

E21: Fazendo conta pra ver se dava pra comprar tudo o que a gente queria.

A estratégia matemática utilizada pelo grupo, além de envolver desconto, como fez o grupo anterior, baseou-se em exemplo da própria vivência dos alunos. Ao rememorar os conselhos dados por sua mãe, 0 estudante 23 confirma que nossa relação com a matemática começa desde a tenra idade. Arriscamos chamar essa estratégia de "matemática de mães" por ser algo que, além de nos ajudar em tomadas de decisão importantes, também contribui para que sejamos inseridos em práticas sociais em que o conhecimento matemático é fundamental. 
Nesse âmbito, a matemática, enquanto ciência e atividade humana, por meio de práticas sociais importantes, é encontrada em nosso cotidiano como descrito pelo estudante 23. De acordo com Tozetto (2010, p. 61), uma das funções do professor que ensina matemática é contribuir para a (re)construção de um conhecimento matemático que "[...] esteja relacionado com os fenômenos matemáticos que acontecem no meio sociocultural de seus alunos, para que eles percebam que a matemática está presente no seu mundo concreto e vivido". Com esse pensamento, questionamos cursos de formação de professores em que os futuros docentes não têm garantida uma formação adequada que os habilite a exercer a função prevista por Tozetto (2010). Todavia, acreditamos na matemática do cotidiano como importante conhecimento para uma prática docente que valoriza os saberes da experiência trazidos pelos alunos quando chegam à escola.

Após mais algumas reflexões com os estudantes, estes corroboraram o que lemos em trabalhos que tratam do letramento matemático, ou seja, o conhecimento de pequenos cálculos e de operações simples é algo presente nas relações comerciais, necessárias no dia a dia das pessoas.

P: Em que momento vocês usaram a matemática?

E7: Na hora de comprar porque a gente precisava saber o preço pra não ser enganado.

P: Alguém enganou vocês?

E7: Não, porque eu fiz a conta e aí sabia quanto era o troco.

Afirmar que conhecimentos matemáticos são necessários para a realização de compras para "não ser enganado" significa apresentar, pelo menos, duas habilidades de quem pode ser considerado matematicamente letrado, conforme observado por Grando (2016): a habilidade de analisar situações e a de resolver problemas que envolvam o conhecimento em matemática. Nesse sentido, 0 estudante 7 também revela compreensão de operações monetárias simples que 0 ajudam no momento de efetivar uma compra, o que é confirmado quando ele assegura haver executado cálculos e, por esse motivo, sabia quanto deveria receber de volta.

Salientamos a relevância de, na atualidade, alunos de anos iniciais serem motivados pelos professores à resolução de problemas cotidianos básicos que envolvam a moeda brasileira. Mendes, Trevisan e Buriasco (2012, p. 08), inspiradas pelas ideias de De Lange (2003), concluem que "[...] é imprescindível que o professor propicie aos estudantes situações de contextos sociocultural, escolar, familiar, pessoal, entre outros, de tal forma que a Matemática seja vista como um conhecimento que nos ajuda a resolver problemas". Nesse sentido, a Base Nacional Comum Curricular (BRASIL, 2016, p. 281) entende que, desde o primeiro ano do ensino fundamental, uma das habilidades a serem desenvolvidas pelos alunos, relativas ao estudo do sistema monetário brasileiro, refere-se a: "Reconhecer e relacionar valores de moedas e cédulas do sistema monetário brasileiro para resolver situações simples do cotidiano do estudante".

Com uma estudante que esteve na função de vendedora durante a atividade, destacamos 0 seguinte diálogo:

P: Na sua opinião, qual a função de uma vendedora?

E18: Ajudar os clientes a comprar.

P: 0 que é preciso para ser vendedora?

E18: Saber vender e fazer cálculos.

P: Por que os cálculos são importantes? 
E18: Pra gente saber o valor certo das coisas e não errar.

P: Você acha importante não errar em matemática?

E18: Sim.

P: Por que?

E18: Ah, porque se a gente errar algum número a conta também vai ficar errada e a gente sabe que a matemática não erra.

Coerentemente com as análises realizadas até o momento, uma vez mais atribuímos destaque à fala da estudante com referência ao uso social que podemos fazer do conhecimento matemático nas relações cotidianas. Na visão da estudante, o bom vendedor seria um indivíduo que, além de saber vender, também faz uso de cálculos, próprios de quem se apropriou de elementos estatísticos básicos para se desenvolver na vida. Ainda segundo as observações feitas pela estudante, a matemática não admite erros e, por esse motivo, é fundamental que um vendedor não cometa deslizes matemáticos. Esse pensamento vai ao encontro do que a BNCC (BRASIL, 2016) afirma em relação à natureza da matemática ao considerá-la uma ciência hipotético-dedutiva. A imagem 4 ilustra 0 momento em que a estudante assume o papel de vendedora e, manuseando as cédulas sem valor, realiza cálculos seguros que satisfaçam a relação de compra e venda.

Figura 4 - Estudante no papel de vendedora.

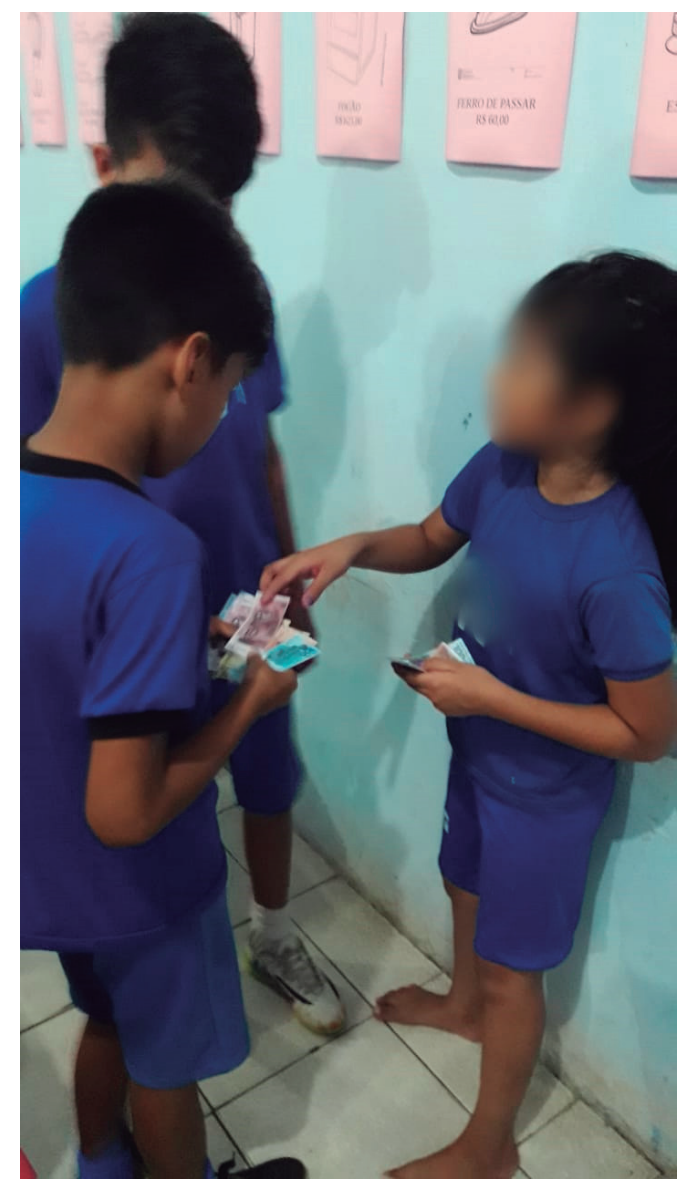

Fonte: Arquivo dos autores. 
Finalizando o estudo, nosso diálogo com os alunos se manteve no sentido de entender até que ponto a prática pedagógica, insubordinada criativamente, gerou aprendizagem significativa e contribuiu para as tomadas de decisão dos estudantes mediante a situação que lhes apresentamos. Por meio de exemplos práticos e de metáforas eles assim se expressaram:

\section{P: 0 que vocês aprenderam com essa atividade?}

E11: Aprendemos a gastar com cuidado.

E9: Eu aprendi que economizar é bom porque sobra mais dinheiro.

P: E você conseguiu economizar?

E9: Sim. Eu pedia desconto quando fazia uma compra. Aí eu calculava pra poder saber quanto tinha economizado.

P: 0 que aprenderam em relação à matemática?

E20: Que ela tá presente na nossa vida.

P: Vocês conseguem dá um exemplo disso?

E3: Por exemplo, todos os dias a minha mãe manda eu comprar açaí e eu preciso saber quanto ele custa pra poder pagar e depois conferir o troco.

E15: A matemática também ajuda a gente a saber usar direito o dinheiro.

E14: Na minha casa vende farinha e a gente precisa saber matemática pra poder passar o troco.

De forma ampla, percebemos que os estudantes parecem considerar conhecimentos matemáticos simples todas as vezes que estabelecem alguma relação que envolve 0 sistema monetário brasileiro, além de entenderem que a matemática faz parte do próprio dia a dia. Falas como a da estudante 9 mostram, na prática, a importância da noção de economia como estratégia para poupar dinheiro. Saber administrar com responsabilidade financeira o próprio dinheiro identifica a fala do estudante 14 em relação à sua percepção da relevância da matemática em ações do cotidiano.

A partir de exemplos da própria vivência e utilizando-se de metáforas, os estudantes 3 e 14 contextualizam a resposta do estudante 20 quando este considera a matemática enquanto conhecimento que se insere nas relações sociais com as quais, cotidianamente, estabelecemos alguma espécie de contato. Isto posto, presumimos os exemplos dos alunos como indicadores de quem pode ser considerado matematicamente letrado, fundamentados nas ideias de Ciríaco e Souza (2011), para os quais o letramento matemático está relacionado ao uso específico do conhecimento matemático em situações da vida cotidiana, como no caso da compra do açaí e da venda de farinha evidenciados pelos alunos. A título de informação, tanto 0 açaí quanto a farinha de mandioca, fazem parte da culinária paraense, 0 que justifica a referência feita pelos estudantes.

\section{CONSIDERAÇÕES FINAIS}

Considerando que 0 letramento matemático abrange habilidades matemáticas na perspectiva da resolução de problemas não apenas escolares, mas sociais (GALVÃO; NACARATO, 2013), como no caso hipotético sugerido à turma de alunos do quinto ano do Ensino Fundamental, julgamos que os posicionamentos assumidos pelos estudantes apontam características de cidadãos com capacidade de decisão e postura responsável diante de situações que exigem atitudes seguras.

Reiteramos que, nos anos iniciais da Educação Básica, posturas/propostas pedagógicas desafiadoras na perspectiva da insubordinação criativa (D'AMBROSIO; LOPES, 2014), devem ser con- 
sideradas como orientação pedagógica que aponta para decisões responsáveis, especialmente no ensino de matemática. Atos de insubordinação criativa comumente ganham força por intermédio de professores comprometidos com a qualidade da educação que é oferecida aos alunos, entretanto, coordenadores pedagógicos, gestores escolares ou mesmo os próprios estudantes podem e devem assumir posturas de ousadia pedagógica com fins de melhoria educacional.

A matemática, enquanto disciplina curricular, ensinada e aprendida na escola, mas também fora dela, deve envolver situações-problema na tentativa de aproximá-la, ao máximo possível, do que os alunos vivenciam em sua realidade. Especialmente nos últimos diálogos apresentados notamos a referência direta a situações do cotidiano que mostram como os estudantes percebem os conhecimentos matemáticos intimamente relacionados à experiência humana.

A maioria das estratégias matemáticas assumidas pelos alunos do quinto ano teve origem em práticas sociais em diferentes contextos nos quais se encontravam inseridos. Isso pode ser evidenciado quando, para tratar da noção de economia, um estudante se reportou à palavra "abatimento", habitualmente utilizada em conversas informais, para se referir a descontos recebidos ao realizar uma compra. Ou ainda quando os alunos recorrem à ideia de "sobrar", com sentido semelhante ao de economizar.

Em síntese, acreditamos que, práticas insubordinadas criativamente na perspectiva do letramento matemático, são propostas pedagógicas ainda pouco desenvolvidas nos anos iniciais, mas que vêm ganhando espaço nas práticas docentes de muitos professores que ensinam matemática nesse nível de ensino. É importante que os educadores desenvolvam suas práticas pensando na formação de indivíduos reflexivos para atuarem na sociedade. Além da participação social, como vimos nos diálogos estabelecidos com os estudantes, o letramento matemático lhes possibilita consciência crítica no sentido de revisitarem posicionamentos e atitudes com vistas ao exercício da cidadania. Assim, Fumeiro et al., (2019, p. 159) afirmam que "[...] a escola deve propiciar situações de ensinoaprendizagem que vise a participação dos sujeitos que a compõem, mediados pelo diálogo, postura reflexiva, autonomia e engajamento social."

Podem-se explorar outros campos da matemática, para além da matemática financeira, de forma insubordinada criativamente, propiciando a tomada de decisão dos estudantes, na perspectiva do letramento matemático escolar, tais como: 0 uso de representações gráficas e por tabelas para a tomada de decisões na formação de um cidadão letrado matematicamente, 0 uso de instrumentos de medidas adequados para as tomadas de decisões em relação à vantagens em aproveitamento espacial, estabelecimento de regularidades e padrões para a otimização na resolução de problemas numéricos e cálculos.

Para além do letramento matemático escolar, é possível ampliar o campo de investigação para as práticas insubordinadas criativamente que venham a contribuir para a tomada de decisões na perspectiva do letramento científico, que envolve 0 uso social, em práticas cotidianas, do conhecimento científico e tecnológico para a resolução de problemas ligados diretamente a contextos da vida humana (MESQUITA, 2019). Mas esse é um tema que fica em aberto para futuras pesquisas.

\section{REFERÊNCIAS}

BRASIL. Ministério da Educação. Base Nacional Comum Curricular. Proposta preliminar. Segunda versão revista. Brasília: MEC, 2016. Disponível em: https://bit.ly/31ndqwA. Acesso em: 04/04/2020. 
CARRAHER, T. N.; CARRAHER, D.; SCHLIEMANN, A. D. Na vida dez, na escola zero. 14ª ed. São Paulo: Cortez, 2006.

CIRÍACO, K. T.; SOUZA, N. M. M. Um estudo na perspectiva do letramento matemático: a matemática das mães. VIDYA, Santa Maria, v. 31, n. 2, p. 41-54, jul./dez., 2011. Disponível em: https://bit.ly/34cUQJu. Acesso em: 04/05/2020.

D’AMBRÓSIO, B. S.; LOPES, C. E. Insubordinação criativa: um convite à reinvenção do educador matemático. Bolema, Rio Claro (SP), v. 29, n. 51, p. 1-17, abr. 2015.

D’AMBRÓSIO, B. S.; LOPES, C. E. Trajetórias profissionais de educadoras matemáticas. 1. ed. Campinas, SP: Mercado de Letras, 2014.

DE LANGE, J. Mathematics for Literacy. In MADISON, B. L.; STEEN. L. A. (Eds.). Quantitative Literacy. Why Numeracy Matters for Schools and Colleges. Princeton, NJ: The National Council on Education and the Disciplines, p. 75-89, 2003.

FUMEIRO, C. L.; SILVEIRA, S. S. S.; MARTINS, S. N.; SILVA, V. J. M. O. Alfabetização científica e tecnológica como princípio da formação do cidadão. Educitec, Manaus, v. 05, n. 11, p. 150-162, jun., 2019.

GALVÃO, E. S.; NACARATO, A. M. O letramento matemático e a resolução de problemas na provinha Brasil. Revista Eletrônica de Educação, v. 7, n. 3, p. 81-96, 2013. Disponível em: https://bit.ly/309zd4s. Acesso em: 05/05/2020.

GARNICA, A. V. M. Insubordinar-se criativamente: inícios, continuidades e (re)inícios. In: D’AMBRÓSIO, B. S.; LOPES, C. E. Trajetórias profissionais de educadoras matemáticas. $1^{a}$ ed. Campinas, SP: Mercado de Letras, 2014, p. 17-22.

GRANDO, R. C. Práticas de letramento matemático escolar na infância: análises de dados e possibilidades. EM TEIA: Revista de Educação Matemática e Tecnológica Íberoamericana, v. 7, n. 1, p. 1-23, 2016. Disponível em: https://bit.ly/ 2HdzpiE. Acesso em: 04/05/2020.

GRANDO, R. C.; NACARATO, A. M.; LOPES, C. E. Narrativa de aula de uma professora sobre a investigação estatística. Educação \& Realidade, Porto Alegre, v. 39, n. 4, p. 985-1002, out./dez., 2014. Disponível em: https://bit.ly/3dlBr60. Acesso em: 08/05/2020.

LONGO, C. A. C. Nós nos constituímos naturalmente insubordinados e, assim, nosso trabalho também... In: D’AMBRÓSIO, B. S.; LOPES, C. E. Ousadia criativa nas práticas de educadores matemáticos (Orgs.). Campinas, SP: Mercado de Letras, 2015, p. 103-131.

MENDES, M. T.; TREVISAN, A. L.; BURIASCO, R. L. C. Possibilidades de intervenção num contexto de ensino e avaliação em matemática. EM TEIA: Revista de Educação Matemática e Tecnológica Iberoamericana, v. 3, n. 1, p. 1-13, 2012. Disponível em: https://bit.ly/3kflBST. Acesso em: 04/05/2020.

MESQUITA, A. S. Ação social responsável: práticas de letramento científico e matemático nos anos iniciais do ensino fundamental. ACTIO: docência em ciências, Curitiba, v. 4, n. 3, p. 309-326, set./dez. 2019. Disponível em: https:// periodicos.utfpr.edu.br/actio. Acesso em: 04/05/2020.

MORRIS, V. C.; CROWSON, R. L.; JR, E. H.; PORTER-GERHIE, C. The urban principal. Discretionary decision-making in a large educational organization. Disponível em: https://eric.ed.gov/?id=ED207178. Acesso em 21/04/2020. 
RIBEIRO, S. Alfabetização matemática: literatura e geometria integradas em uma experiência lúdica. In: CARNEIRO, F. R.; SOUZA, A. C.; BERTINI, L. de F. (Orgs.). A matemática nos anos iniciais do ensino fundamental: práticas de sala de aula e de formação de professores. Brasília, DF: SBEM, 2018, p. 33-48.

SILVA, A. H.; TRINTIN, R. da S. Uma análise qualitativa dos conceitos básicos de Astronomia dos professores dos Anos Iniciais do Ensino Fundamental. ACTIO: docência em ciências, Curitiba, v. 2, n. 1, p. 304-320, jan./jul. 2017. Disponível em: https://periodicos.utfpr.edu.br/actio. Acesso em: 22/04/2020.

SOARES, M. Letramento: um tema em três gêneros. 2. ed. 9. reimp. Belo Horizonte: Autêntica, 2004.

TOZETTO, A. S. Letramento para a docência em matemática nos anos iniciais do ensino fundamental. Dissertação (Mestrado em Educação). Universidade Estadual de Ponta Grossa, Ponta Grossa, 2010.

RECEBIDO EM: 02 jun. 2020

CONCLUÍDO EM: 21 ago. 2020 
